\title{
Northern Australian pasture and beef systems. 2. Validation and use of the Sustainable Grazing Systems (SGS) whole-farm biophysical model
}

\author{
Natalie A. Doran-Browne ${ }^{\mathrm{A}, \mathrm{D}}$, Steven G. Bray ${ }^{\mathrm{B}}$, Ian R. Johnson ${ }^{\mathrm{A}}$, Peter J. O' Reagain ${ }^{\mathrm{C}}$ \\ and Richard J. Eckard ${ }^{\mathrm{A}}$

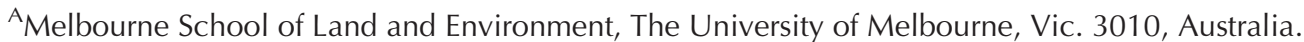 \\ ${ }^{B}$ Department of Agriculture, Fisheries and Forestry, PO Box 6014, Rockhampton, Qld 4702, Australia. \\ ${ }^{C}$ Department of Agriculture, Fisheries and Forestry, PO Box 976, Charters Towers, Qld 4820, Australia. \\ ${ }^{\mathrm{D}}$ Corresponding author. Email: n.doran-browne@unimelb.edu.au
}

\begin{abstract}
The Sustainable Grazing Systems (SGS) model is a biophysical, mechanistic whole-farm model that simulates pasture production based on climate and soil data. While the SGS model has been extensively used for southern temperate systems, the model has yet to be evaluated for use in the tropical rangeland systems of Australia. New pasture parameter sets were developed in SGS to represent groups of grasses with the following common characteristics: (1) 3P grasses represented tropical rangeland grasses that were perennial, palatable and productive, and (2) annual tropical grasses that include both productive and less productive grass species. Fifteen years of data from the long-term Wambiana grazing trial $\sim 70 \mathrm{~km}$ south-west of Charters Towers, Queensland, were used to validate the model. The results showed that SGS is capable of representing northern Australian beef systems with modelled outputs for total standing dry matter and steer liveweight in agreement with the year-to-year variation in measured data over three different soil types and two stocking rates. Recommendations for further model development are made, such as incorporating fire, tree growth and the use of urea supplementation in the model. Further testing is required to verify that the new pasture parameter sets are suitable for other regions in northern Australia.
\end{abstract}

Additional keywords: cattle, modelling, rangelands.

Received 13 May 2014, accepted 1 August 2014, published online 20 October 2014

\section{Introduction}

Low and declining profitability and poor productivity are impacting on the sustainability of northern Australia beef businesses (McLean et al. 2014). A range of principles and management guidelines have been proposed to improve beef business profitability and sustainability in northern Australia such are improving reproductive rates and managing stocking rates to meet goals for livestock production and land condition (Hunt et al. 2014; McLean et al. 2014). Whole-farm models offer a cost-effective way of exploring farm management issues or revealing which research areas or management options require further study. Models can examine a range of scenarios by simulating how a farm system would perform under particular management options or environmental conditions, such as applying a range of stocking rates or herd structures, assessing the performance of pastures in particular climatic regions or soil types, or examining how a farm performs across years of low or extreme rainfall (e.g. O'Reagain et al. 2014). Farms are complex systems due to the numerous components that exist such as livestock, various pastures species or soil properties, and particularly, because of the interactions that take place between each of these components in response to climate. Whole-farm models enable the relationships that exist between farm components to be incorporated into one complete system that can be analysed over many years.

The Sustainable Grazing Systems (SGS) model is a biophysical, mechanistic model that includes modules for soil water and nutrient balance, pasture production and utilisation of multiple species, and animal intake and growth (Johnson et al. 2003). In SGS, animal intake is affected by available herbage, and grazing consequently influences herbage accumulation and growth (see Johnson et al. 2003). The SGS model uses a daily time-step and incorporates complex interactions between these modules. Most of the processes in SGS are determined by climate, particularly rainfall, temperature, solar radiation and vapour pressure deficit (or humidity). Farm performance is influenced by various selected farm management options such as the stocking rate regime, pasture species, fertiliser regime or irrigation schedule. Additionally, SGS is able to predict the greenhouse gas emissions $\left(\mathrm{CH}_{4}\right.$ and $\left.\mathrm{N}_{2} \mathrm{O}\right)$ from the farm as well as soil carbon fluxes (Johnson et al. 2008). 
As a mechanistic model, SGS differs from the existing empirical model, GRASP, that has been used extensively for tropical rangeland systems in northern Australia (Scanlan et al. 2013). Empirical models use experimental data to describe what is occurring and to form single level relationships but these relationships may not be based on underlying biological processes (France and Kebreab 2008). Mechanistic models seek to understand underlying processes and examine the structure of the system, dividing it into modules and then analysing the performance of the whole system, as well as the connections between each of the modules (France and Kebreab 2008). SGS has been extensively used to model southern, temperate systems in numerous studies at various sites across southern Australia (see Graham et al. 2003; Lodge et al. 2003; Sanford et al. 2003; Cullen et al. 2008), but has yet to be tested for use in Australian tropical rangeland grazing systems. Models need to be evaluated to determine whether they perform acceptably for their anticipated purpose (Araújo and Guisan 2006). Although there has been debate over the term validation and the validation process when testing models (Oreskes et al. 1994), here the term validation is used to demonstrate whether the model is acceptable for its intended use (Rykiel 1996). This validation is performed by comparing simulated and observed data, a method of evaluation that is widely used (Clark et al. 2000; Bell et al. 2013; Pembleton et al. 2013; Scanlan et al. 2013). The aim of this paper is to validate the SGS model to determine if the model can produce a realistic simulation of a selected northern Australian beef system. The Wambiana grazing trial provides an opportunity to assess factors around beef business profitability, sustainability, net carbon position and validate a range of models (O'Reagain et al. 2011; Scanlan et al. 2013; Bray et al. 2014). Additionally, this paper identifies further developments in SGS to help improve how the model represents tropical Australian grazing systems by simulating the long-term grazing trial at Wambiana.

\section{Methods}

\section{The Wambiana site}

The Wambiana grazing experiment is a long-term research site (1997-2014) situated $\sim 70 \mathrm{~km}$ south-west of Charters Towers, Queensland $\left(20^{\circ} 34^{\prime} \mathrm{S}, 146^{\circ} 07^{\prime} \mathrm{E}\right)$ on a commercial beef property. Long-term (1905-2012) average annual rainfall for the site is $640 \mathrm{~mm}$ but is highly variable (range of 207-1409 mm) with rainfall largely summer-dominant (O'Reagain et al. 2011). There are three main soil types each associated with distinct types of savanna woodland: (1) moderately fertile brown sodosols and chromosols dominated by Reid River box (Eucalyptus brownii), (2) more fertile grey earths and vertosols dominated by brigalow (Acacia harpophylla) and (3) well drained, low fertility yellow/red kandosols dominated by silver-leaf ironbark (E. melanophloia) (O'Reagain et al. 2009). These three soil types will be referred to as the box, brigalow and ironbark soil types, respectively. The trial paddocks at Wambiana were fenced so that each paddock had roughly the same percentage of the three major soil types. Therefore, $55 \%$ of the paddock areas had the box soil type, $22 \%$ was brigalow and the remaining $23 \%$ of the paddock was ironbark (O'Reagain and Bushell 2011) and cattle were free to selectively graze on any of these soil types within each paddock.

The site was dominated by native $\mathrm{C}_{4}$ grasses with all soils having some 3P species (defined as perennial, productive and palatable grasses). The box soil type was dominated by $3 \mathrm{P}$ (Chrysopogon fallax and Bothriochloa ewartiana), as was the brigalow soil (Dichanthium sericeum and Bothriochloa ewartiana) and the ironbark soil mainly had unpalatable grasses (Eriachne mucronata and Aristida spp.) yet also contained around 30\% of 3P grasses Chrysopogon fallax and Heteropogon contortus (O'Reagain et al. 2009). Pasture data were measured annually from 1998 to 2012 using the BOTANAL procedure (Tothill et al. 1992) at the end of the wet season (May), which was close to the annual peak of pasture mass.

Five different stocking strategies were applied at the Wambiana trial with two of these, the moderate stocking rate (MSR) and heavy stocking rate (HSR), used in this modelling study and in the companion study assessment of the net carbon position at Wambiana (Bray et al. 2014). The MSR had 8-10 ha/ animal equivalent (where $1 \mathrm{AE}=\mathrm{a} 450-\mathrm{kg}$ steer; McLean and Blakeley 2014) and the HSR had 4-5 ha/AE (O'Reagain et al. 2009). Steers with similar genetics were purchased every year in June from James Cook University research station $100 \mathrm{~km}$ north of the trial, or from a property $\sim 120 \mathrm{~km}$ west of Charters Towers (O'Reagain et al. 2009). Prior to 2001 steers were sold after 1 year but from 2001 onwards, steers were kept for 2 years with a new group still purchased each year. The average animal starting weight from 2001 was 239-391 kg and before 2001 the average starting weight was 239-305 kg. Steers were weighed on entry to the Wambiana site and every 6 months thereafter until the steers were sold 2 years later in June. Steers were destocked for 3 months in 2004 from one of the HSR paddocks as a result of drought. Urea lick blocks were supplied to both treatments in the Dry season in 2003 with urea subsequently supplied as dry loose-mix in tubs until 2012. Further details of the Wambiana long-term experiment are detailed in O'Reagain et al. (2011).

\section{Model simulations}

The area modelled was scaled up to 1000 ha to avoid errors in rounding animal numbers, which may have occurred if the paddocks were kept at their original size of $\sim 100$ ha. Each soil type was modelled as a separate simulation in SGS and the area for box, brigalow and ironbark therefore consisted of 550, 220 and 230 ha, respectively.

The MSR and HSR treatments were modelled at $8 \mathrm{ha} / \mathrm{AE}$ and 4 ha/AE, respectively, across the whole 1000-ha simulation. Previous research using GPS collars (Tomkins et al. 2009) had demonstrated that steers at the Wambiana site had a preference for grazing on brigalow soil, followed by the box soil and then the ironbark soil. To reflect this preference, the number of steers that could be sustained on each soil type was calculated using the fodder budgeting program Stocktake (FutureBeef 2014), which is a paddock-scale software program that uses land condition and grass growth predictions to calculate the carrying capacity of a particular soil type. Based on Stocktake the calculated carrying capacity for the box, brigalow and 
ironbark soils were $3.8,2.8$ and 7.9 ha/AE (or $58 \%, 31 \%$ and $11 \%$ of total stock), respectively, and were therefore the stocking rates used for each soil type in SGS. When the different land sizes for each soil type were taken into consideration, these three stocking rates equalled $4 \mathrm{ha} / \mathrm{AE}$ for the HSR treatment over the total 1000 ha. The MSR had half the number of stock of the HSR and therefore the stocking rates for the box, brigalow and ironbark soils were set in SGS at 7.6, 5.6 and $15.8 \mathrm{ha} / \mathrm{AE}$ (or $58 \%, 31 \%$ and $11 \%$ of total stock), respectively. A single starting weight was required in SGS and therefore, although there was variation in animal starting weights across the years, $330 \mathrm{~kg}$ was used, which was the average starting weight of steers from 2001 to 2012. Since each soil type was modelled separately in SGS, there were different liveweight figure outputs for each soil type. These liveweight figures then needed to be combined and the final steer liveweight was calculated by multiplying the liveweight of steers by the percentage of stock on the particular soil type and then adding the liveweights together.

The model was run from January 1988 to December 2012, with the first 10 years being discarded to allow the parameters in the model to settle. However, a longer period was required for the soil carbon to stabilise and therefore the 'loop' function was used in SGS for 10 rotations, which runs through the model 10 times, allowing soil carbon to stabilise over a longer period. SILO data drill daily climate data was used (see www.longpaddock.qld.gov.au/silo/, verified 1 March 2014) for the research site.

\section{Pasture parameter sets for $3 P$ grasses and tropical annual grasses}

SGS simulates paddocks with multiple pasture species, but it is common for over a hundred pasture species to grow in the northern Australian rangelands at the paddock scale. Incorporating a vast number of species in SGS is impractical, and so pastures were modelled according to grouped species. Pasture parameter sets were developed in SGS for two new pasture groups: (1) 3P grasses that grow quickly in response to rain and are an important part of profitable tropical rangeland grazing systems, and (2) annual grasses that incorporate a range of grasses from tropical rangeland grazing systems. Grasses, forbs, sedges and native legumes usually consisted of $<10 \%$ of total standing dry matter (TSDM) and were ignored. Unpalatable grasses (Eriachne mucronata and Aristida spp.) were also excluded from the simulation and measured TSDM data points.

SGS is a mechanistic model, thus all parameters have an underlying biophysical interpretation, and so the strategy for parameterising the plant species is to focus on the underlying physiology. For example, the rates of transfer of standing dead material to litter were taken to be $0.3 \%$ per day for the perennial pastures but the higher value of $1 \%$ per day was used for the annual grasses. Root depth for $3 \mathrm{P}$ and annual grasses were taken to be $100 \mathrm{~cm}$ and $60 \mathrm{~cm}$, respectively (Murphy 2010). The percentage of new shoot growth allocated to leaf was defined as $45 \%$ for both $3 \mathrm{P}$ and annuals, which is considerably lower than is generally applied to temperate species, reflecting morphological differences. Likewise, specific leaf area at ambient $\mathrm{CO}_{2}\left(\mathrm{~m}^{2}\right.$ leaf $/ \mathrm{kg}$ dry weight) was 15 , which is lower than what is usually seen in temperate species and the amount of $\mathrm{N}$ uptake was $1000 \mathrm{~g} \mathrm{~N} / \mathrm{t}$ root dry weight/parts per million/ day for $\mathrm{NO}_{3}$ and $\mathrm{NH}_{4}$ uptake. Additionally, the annual grasses were assumed to have a lower grazing preference, digestibility and leaf $\mathrm{N}$ than $3 \mathrm{P}$ grasses.

\section{Analysing the data}

The observed and modelled pasture data analysed were TSDM in $\mathrm{t} / \mathrm{ha}$, which included green and dry herbage but not litter, the amount of 3P grasses and annual grasses and steer liveweight $(\mathrm{kg})$.

Several evaluation statistics based on Tedeschi (2006) were used to compare modelled and observed values for TSDM of pasture. The statistics calculated were measured mean; modelled mean; mean bias, being the difference between the measured and modelled mean; coefficient of determination $\left(r^{2}\right)$ as a measure of precision; mean prediction error, which indicated the efficiency of the model as a percentage of the mean; model efficiency indicated the amount of variance between the measured and modelled output with 1 signifying a perfect fit; variance ratio was the level of variance in the observed and simulated values and a value of 1 showed the same level of variance; bias correction factor showed how far the regression line moved from the slope of $y=\times$ with a value of 1 meaning there is no bias; and the concordance correlation coefficient (Lin 1989) was a measure of both accuracy and precision with a value of 1 indicating a perfect fit. The number of observations for TSDM was 90 in total i.e. $2 \times$ stocking rate treatments $\times 3$ soil types $\times$ 15 years. The observed values were the average of measurements from each replication taken in May and modelled values were the average of a month's pasture before 1 May, to capture some of the variation that is expected around the measured point. The number of observations for steer liveweight was 94 and the coefficient of determination $\left(r^{2}\right)$ and mean prediction error were also calculated for the observed and modelled liveweights.

\section{Results}

The measured and simulated outputs for TSDM for each dataset are presented in Fig. 1. The SGS model represented the year-toyear variation in pasture production well with a significant relationship $(n=90, P<0.001)$ and a variation $\left(r^{2}\right)$ of 0.60 between the modelled and observed TSDM. The modelled results for the HSR were mostly clustered towards the lower end due to reduced herbage mass from heavier grazing; however, there was greater variation between observed and modelled values in the TSDM results for HSR than the MSR treatment. The mean across all measured TSDM data was $1.68 \mathrm{t}$ $\mathrm{DM} / \mathrm{ha}$, compared with a mean of $1.80 \mathrm{t} \mathrm{DM} /$ ha for all modelled outputs and the mean bias was therefore $-0.12 \mathrm{t} \mathrm{DM} / \mathrm{ha}$. The mean prediction error was $47 \%$ and model efficiency, which ideally should be above 0.50 , was 0.57 . The variance between observed and modelled values was 1.09, indicating that there was greater variation in the measured data than in the simulated data. The bias correction factor was 0.99 , indicating that there was only minor deviation from the $1: 1$ line and the concordance correlation coefficient had slightly greater variation at 0.76 .

The contribution to yield of $3 \mathrm{P}$ and annual grasses are shown for each of the soil types in Fig. 2 and Fig. 3 for the MSR and 
HSR treatments, respectively. Modelling species composition can be difficult due to competition effects and grazing characteristics, but SGS managed to represent the measured

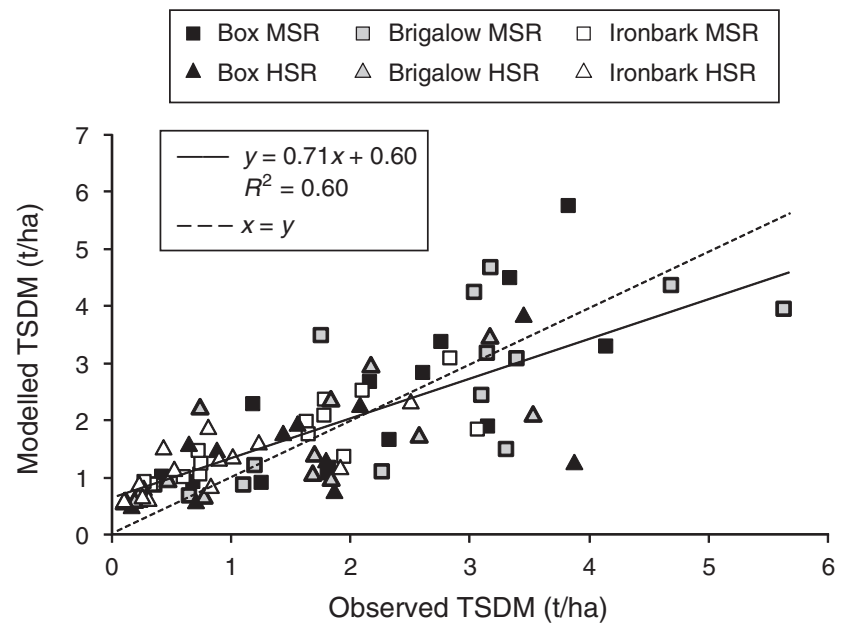

Fig. 1. Measured and simulated total standing dry matter (TSDM) for the moderate stocking rate (MSR) and heavy stocking rate (HSR) on box, brigalow and ironbark soil types. pattern of 3P and annual grass growth adequately. The modelled pasture growth reflected the reduced annual rainfall (July-June) in 2001-02 to 2005-06 of 350-518 mm, compared with an annual rainfall of 558-1196 mm for the other years. As expected, differences in productivity could also be observed across the various soil types. The brigalow soil was the most productive of the three soil types and despite having a relatively higher grazing pressure, produced roughly the same amount of TSDM as the box soil. In contrast, the ironbark soil, being both less fertile and sandier, retained less water than the other two soil types and hence produced less pasture. Additionally, the seasonal and year-to-year differences in liveweight gain are shown in Fig. 4 for both MSR and HSR stocking rate treatments. The variation in liveweight $\left(r^{2}\right)$ was also 0.60 with a significant relationship $(n=94, P<0.001)$ and a mean prediction error of $18.5 \%$.

\section{Discussion}

The results demonstrate that the SGS model can realistically represent pasture TSDM and the relative contribution to yield of $3 \mathrm{P}$ and annual grasses over both multiple soil types (Fig. 1) and different stocking rates (Figs 2 and 3). Additionally, the modelled animal liveweight and liveweight gain showed a good

(a) Box

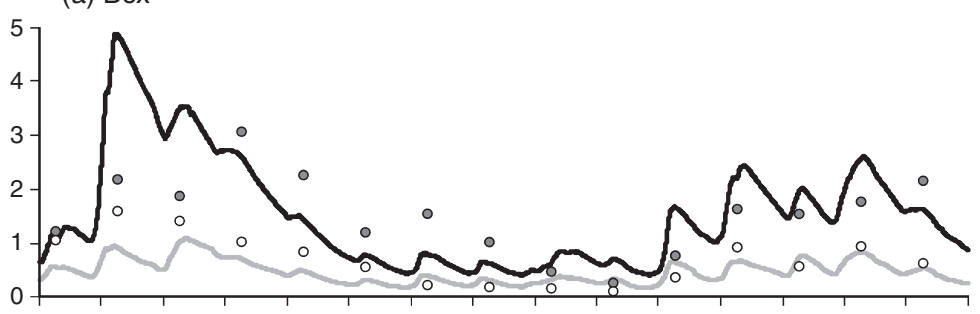

(b) Brigalow

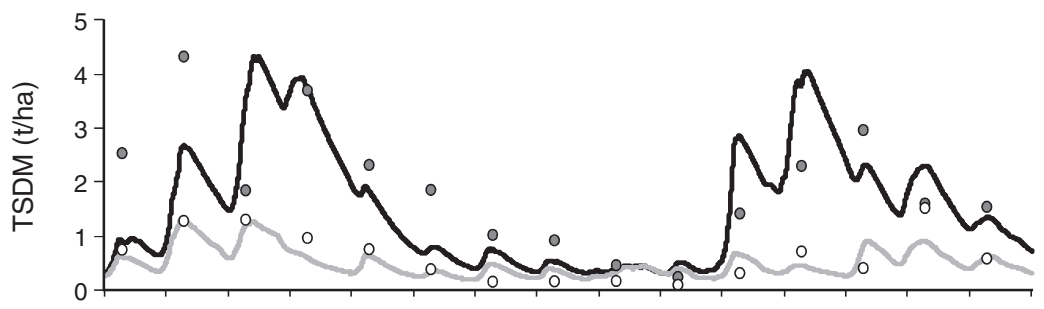

(c) Ironbark

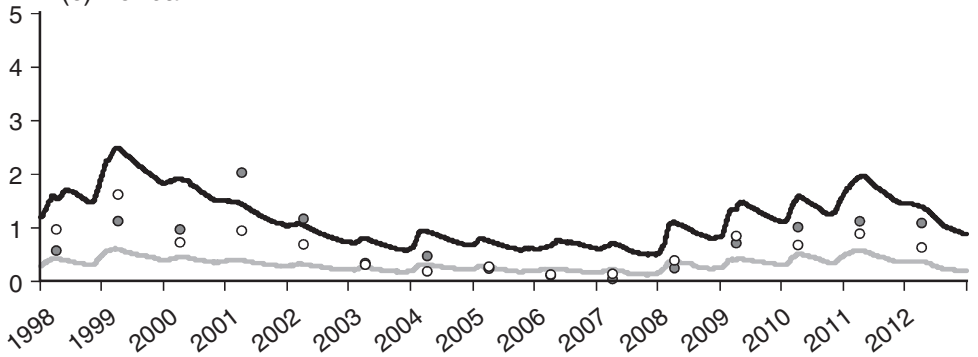

Fig. 2. Measured (points) and simulated (lines) total standing dry matter (TSDM) of 3P (black lines and points) and annual grass (grey lines and points) species composition for (a) box, $(b)$ brigalow and $(c)$ ironbark soil types for the moderate stocking rate treatment. 

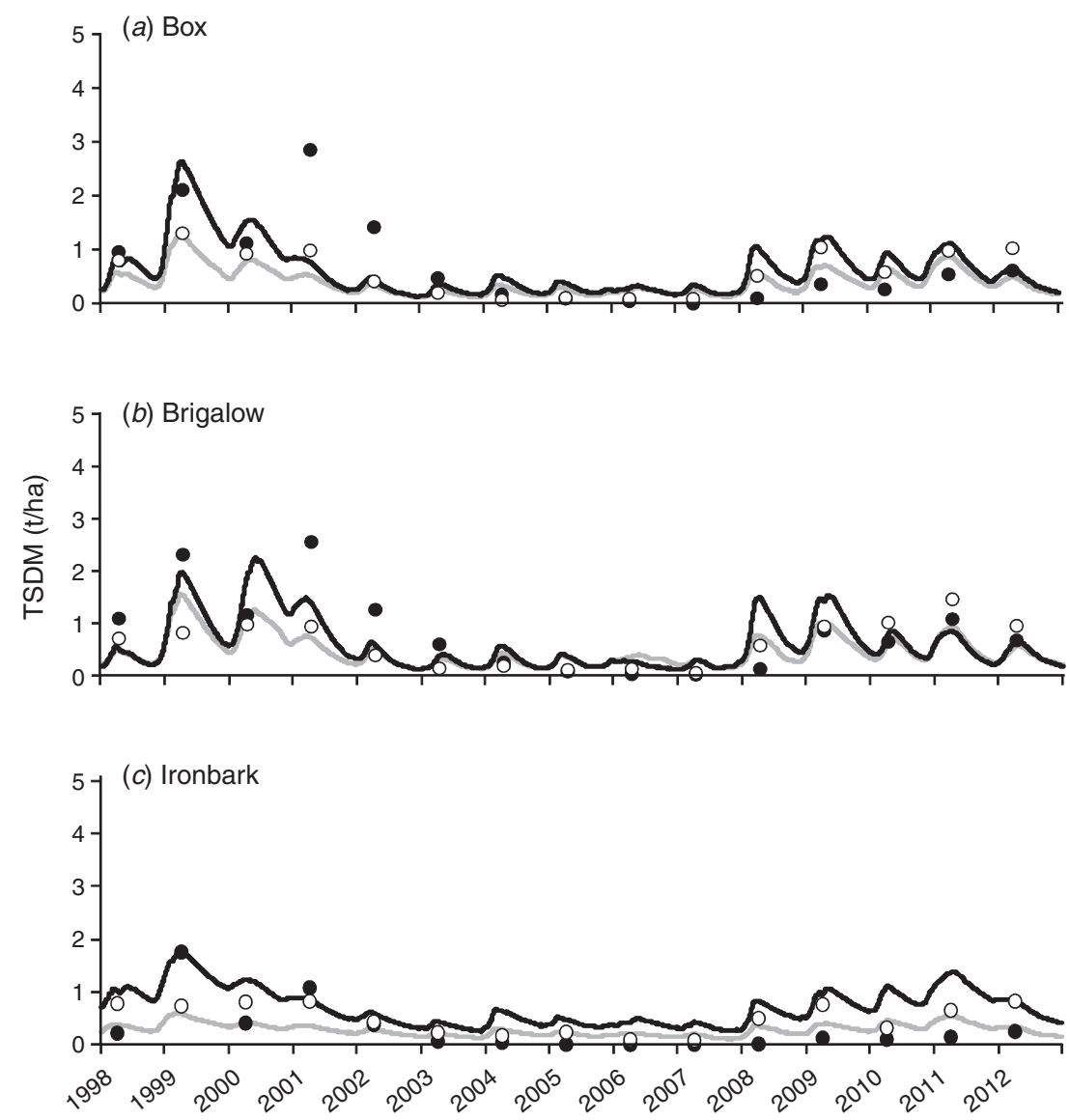

Fig. 3. Measured (points) and simulated (lines) standing dry matter (TSDM) of 3P (black lines and points) and annual grass (grey lines and points) species composition for $(a)$ box, $(b)$ brigalow and $(c)$ ironbark soil types for the heavy stocking rate treatment.

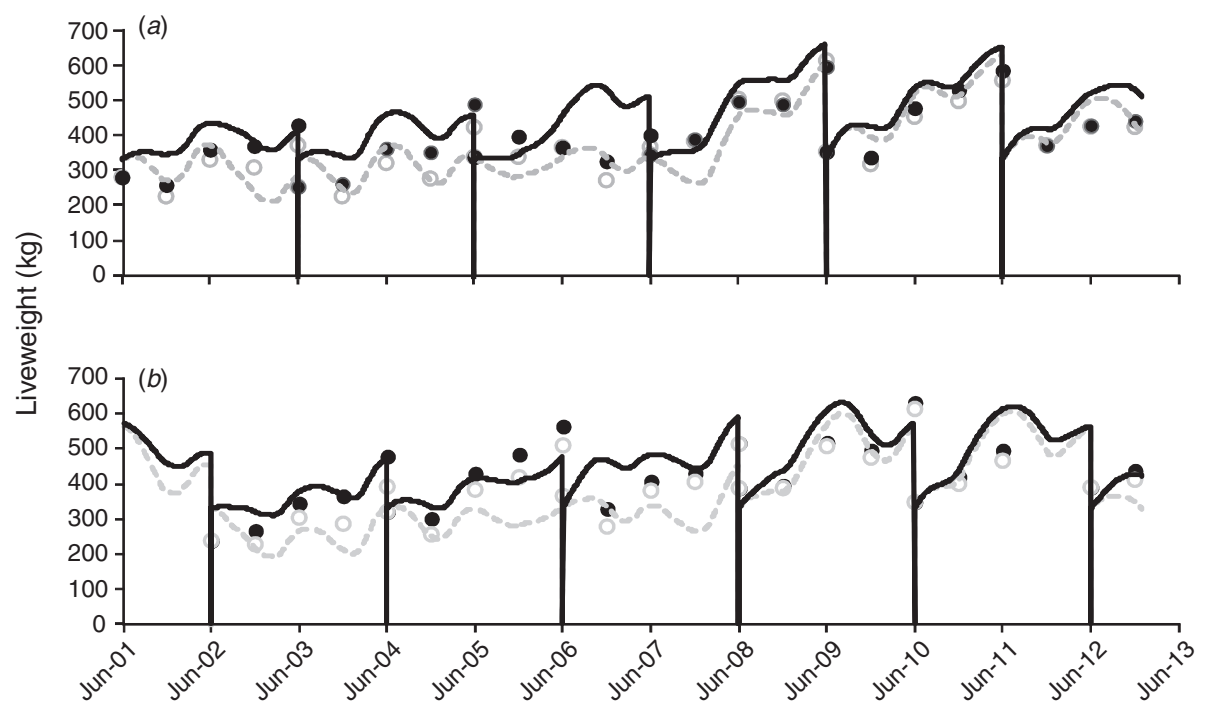

Fig. 4. Measured (points) and modelled (lines) steer liveweight with animals purchased in $(a)$ odd numbered years and $(b)$ even numbered years. Steers remained on the farm enterprise for 2 years for the moderate stocking rate (black lines and points) and the heavy stocking rate measured (grey lines and points). 
representation $\left(r^{2}=0.60\right)$ of the measured liveweight of steers at the Wambiana site (Fig. 4). TSDM across the whole dataset produced a mean bias of $-0.12 \mathrm{t} / \mathrm{ha}$ and although the mean prediction error at $47 \%$ was above what is usually considered to signify model accuracy $(<20 \%)$ the results were similar to other studies using pasture and grazing models (Jouven et al. 2006; Robertson 2006; Cullen et al. 2008).

There are challenges with comparing observed and simulated TSDM data in grazing systems. Variation in the results can occur due to sampling and measurement error, limitations in the model, or a combination of both. The variation from measured data may also occur due to the difficulty in accurately measuring pasture mass (Cullen et al. 2008), particularly in large spatially variable paddocks and the uncertainties associated with comprehensively capturing all aspects of the growth conditions (White et al. 2008). There was a discrepancy between the measured and modelled data in the wet season of 2006-07 with modelled steers in the MSR paddock having greater liveweight gain than at the Wambiana site (Fig. 4a). During this time there was reduced pasture availability and a decline in pasture vigour due to the preceding dry years, yet this was the only point where the measured liveweight data had a different growth pattern to other years, which would have been influenced by changes in management (e.g. the introduction of urea feeding) at that time. There may also have been an inconsistency in the measured data, or it may point to the inability of the model to adequately represent changes in species composition, reduced plant vigour and changes in nutrient cycling that may occur under drought and subsequent drought recovery. There were some variations at the Wambiana site that could not be captured in the model, such as steers at the site being kept for only 1 year between 1998 and 2001, which may have influenced the amount of TSDM available during these years due to different patterns in liveweight gain and consequently rates of pasture intake.

Pasture TSDM can also vary markedly across paddocks due to spatial variability in rainfall, patch grazing (Hirata 2000) and underlying soil heterogeneity, even within soil types. This spatial variability has been studied by Pringle et al. (2011) who noted that soil organic carbon was influenced to a depth of $0.3 \mathrm{~m}$ in the soil due to the interaction between soil type and grazing pressure. Data from the Wambiana site was averaged across two replicate paddocks and there were instances where these differed in TSDM by up to $2 \mathrm{tDM} / \mathrm{h}$ a for the same stocking rate and soil type. This amount represents a large range of acceptable TSDM values in the paddock. Therefore, while the modelled output may have been within the range of observed values, at times the modelled outputs appeared less accurate when compared with the paddock average. There was additional variability as a result of modelling multiple species as a group, which in reality vary in forage quality and growth characteristics between species, particularly for the annual grasses. However, these annual grasses usually comprised a smaller amount of TSDM than the $3 \mathrm{P}$ grasses and therefore this additional variation would have had less of an effect on the overall simulation than differences when modelling multiple 3P grasses.

Modelling work has also been conducted for the Wambiana site by Scanlan et al. (2013) using the empirical model GRASP, which produced a close relationship between observed and modelled values for TSDM at the paddock level of $r^{2}=0.82$, compared with $r^{2}=0.60$ in this study. However, the GRASP study looked at the box soil type only, whereas the relationship in SGS was for the box, brigalow and ironbark soil types. Similar difficulties existed in both models for matching observed liveweight during 2004-05 and 2006-07, however these years were excluded from the GRASP analysis, producing a good relationship $\left(r^{2}=0.64\right)$, which was similar in SGS $\left(r^{2}=0.60\right)$. In general, empirical models, where parameters are fitted directly to observational data, tend to give closer agreement than mechanistic models (Thornley and Johnson 2000). However, while outputs from mechanistic models tend to be more variable than those from empirical models, mechanistic models provide greater insight and understanding of the underlying biophysical process and the relationships that exist, such as the interaction between soil properties, pasture growth and animal intake. Additionally, mechanistic models are less site-specific because they can be more easily applied to other sites than empirical models, which are tied to the database used to create it (France and Kebreab 2008). As SGS is a mechanistic model, all model parameters have an underlying biophysical interpretation. By defining species characteristics through the key parameter values defined in the methods, we have been able to demonstrate that the model simulations are in agreement with observed values.

For example Cullen et al. (2008), using the same set of physiological parameters for perennial ryegrass, demonstrated good agreement between the model and observations for a wide range of locations in Australia and New Zealand. As mentioned earlier, Oreskes et al. (1994) highlight possible limitations when comparing models with experimental data within complex natural systems. This is apparent in the present work where we were unable to incorporate all management strategies that were applied at the site in the model simulations. It is important, therefore, that we look for consistency in the simulated output as well as agreement with the data. For example, the lower simulated liveweights during 2006-07 are consistent with the lower pasture growth rates due to lack of rain and reflect the fact that, in the simulations, the stock were not removed from the paddock or fed supplements.

There are some further developments of the SGS model that would help improve the model predictions of TSDM and animal liveweight. First, while SGS has a comprehensive way of providing supplementary feeds which are more relevant to temperate grazing systems, there is currently no method for including urea supplementation in the model, which is commonly provided to animals in northern Australia to compensate for low forage protein in dry conditions. Urea supplementation was supplied at the Wambiana site to both treatments during the Dry seasons (May-November) of 2003-04 to 2011-12 and contributed to higher measured liveweights of steers during these years, which can be seen in Fig. $4 b$.

Another useful addition to the SGS model would be a management option to destock during severe drought. In 2004 one of the HSR paddocks at Wambiana was destocked for 4 months due to lack of feed (O'Reagain et al. 2009). Molasses and urea drought feeding was also provided to the 
HSR steers at the Wambiana site for short periods in the Dry season from 2003-04 to 2006-07. The modelled outputs for the HSR (Fig. 4) showed lower liveweights than measured at certain points during 2004 and 2005, which probably reflects these factors.

The ability for pastures to recover following extended periods of drought and heavy grazing as happened in the HSR should be further refined in the SGS model. The modelled pasture recovered more quickly after the drought years than data from the Wambiana site would suggest (see Fig. $2 a$ from 2006 onwards) because the model does not include cumulative effects of consecutive droughts and overgrazing on species survival and consequent growth. While SGS suppressed growth with reduced rainfall, it did not kill the plants and was consequently able to recover more quickly with the return of rain after drought seasons.

The inclusion of a tree component that incorporated tree basal area would assist in the model's representation of tropical rangeland systems. Many Australian tropical rangelands have trees of different sizes that compete with pastures for water and light and this interaction becomes an important consideration for farm management decisions. Northern Australian systems also include fire, which may be used to remove dead forage and/or manage tree density. Although SGS does include fire, regrowth following fire appeared significantly slower than was observed and therefore the fire component was excluded from this study. This is an area that could be explored further.

The development of parameter sets for other pasture species groups such as unpalatable grasses, forbs, other $2 \mathrm{P}$ grasses (that are any two of the following: perennial, productive or palatable), native legumes and invading exotic grasses would be useful. Although these other pasture species comprise a relatively small component of total TSDM at the Wambiana site, the availability of additional pasture parameter sets would increase the model's ability to answer important issues facing rangeland managers in northern Australia.

\section{Conclusion}

We have explored the potential for applying the SGS model to northern Australian beef grazing systems. The analyses presented here demonstrate that the SGS model is able to simulate pasture TSDM and steer liveweight gain in a northern Australian beef system. The model predictions of $3 \mathrm{P}$ and annual grasses were reasonable $\left(r^{2}=0.60\right)$ when compared with observed values over a range of soil types and stocking rates, providing preliminary evidence that the SGS model could be used to simulate these rangeland systems. However, this research would benefit from further testing to verify that the new pasture parameters of $3 \mathrm{P}$ and annual grasses are suitable at other sites across Queensland and the Northern Territory, particularly documenting essential changes to these parameters used in this case study.

Empirical models cannot be used beyond the site of the data that was used to create them without changing the fundamental relationships used in the model. Mechanistic models rely on processes and are valuable once validated in that they can more easily be applied across a variety of rangeland conditions with some predictive ability. While the SGS model would benefit from further validation for tropical rangeland systems, the model is more versatile than an empirical model because it can be transferred more easily to different sites.

There are several recommendations for further model development including the incorporation of urea supplementation for use in the Dry season, the ability to destock during drought, accounting for the effect of trees and tree size into the model, the use of prescribed burning and the development of pasture parameter sets for other species groups such as unpalatable grasses and forbs.

The SGS model has been widely used in temperate and subtropical grazing systems in southern Australia. This paper for the first time provides some evidence that this utility could be extended to tropical rangeland systems, particularly to allow the research from the Wambiana long-term grazing site to be extended to other locations. There is considerable potential to extend the present analysis to other tropical rangeland grazing regions in Australian. The model gives an integrated, balanced treatment of plants, animals, soil water, soil organic matter, nutrient dynamics and greenhouse gas emissions. Given the mechanistic nature of the model, it has potential to be applied in a range of studies, such as risk assessment of management strategies, climate change mitigation, and supplementary feeding regimes.

\section{Acknowledgements}

This work was supported by Dairy Australia, Meat and Livestock Australia, Australian Wool Innovation and the Australian Government Department of Agriculture. The authors are grateful for assistance provided by Joe Scanlan and Brendan Cullen.

\section{References}

Araújo MB, Guisan A (2006) Five (or so) challenges for species distribution modelling. Journal of Biogeography 33, 1677-1688. doi:10.1111/j.13 65-2699.2006.01584.x

Bell MJ, Eckard RJ, Harrison MT, Neal JS, Cullen BR (2013) Effect of warming on the productivity of perennial ryegrass and kikuyu pastures in south-eastern Australia. Crop and Pasture Science 64, 61-70. doi:10.1071/CP12358

Bray S, Doran-Browne N, O'Reagain P (2014) Northern Australian pasture and beef systems. 1. Calculation of greenhouse gas emissions. Animal Production Science

Clark SG, Donnelly JR, Moore AD (2000) The GrassGro decision support tool: its effectiveness in simulating pasture and animal production and value in determining research priorities. Australian Journal of Experimental Agriculture 40, 247-256. doi:10.1071/EA98011

Cullen BR, Eckard RJ, Callow MN, Johnson IR, Chapman DF, Rawnsley RP, Garcia SC, White T, Snow VO (2008) Simulating pasture growth rates in Australian and New Zealand grazing systems. Australian Journal of Agricultural Research 59, 761-768. doi:10.1071/AR07371

France J, Kebreab E (2008) 'Mathematical modelling in animal nutrition.' (CABI: Wallingford, UK)

FutureBeef (2014) Stocktake: balancing supply and demand. Available at http://futurebeef.com.au/resources/workshops/sustainable-grazingworkshops/stocktake-balancing-supply-and-demand/ [Verified 28 April 2014]

Graham JF, Cullen BR, Lodge GM, Andrew MH, Christy BP, Holst PJ, Wang X, Murphy SR, Thompsona AN (2003) SGS Animal Production Theme: effect of grazing system on animal productivity and 
sustainability across southern Australia. Australian Journal of Experimental Agriculture 43, 977-991. doi:10.1071/EA02197

Hirata M (2000) Quantifying spatial heterogeneity in herbage mass and consumption in pastures. Journal of Range Management 53, 315-321. doi: $10.2307 / 4003439$

Hunt LP, McIvor JG, Grice AC, Bray SG (2014) Principles and guidelines for managing cattle grazing in the grazing lands of northern Australia: stocking rates, pasture resting, prescribed fire, paddock size and water points - a review. The Rangeland Journal 36(2), 105-119. doi:10.1071/ RJ13070

Johnson IR, Lodge GM, White RE (2003) The Sustainable Grazing Systems Pasture Model: description, philosophy and application to the SGS national experiment. Australian Journal of Experimental Agriculture 43, 711-728. doi:10.1071/EA02213

Johnson IR, Chapman DF, Snow VO, Eckard RJ, Parsons AJ, Lambert MG, Cullen BR (2008) DairyMod and EcoMod: biophysical pasturesimulation models for Australia and New Zealand. Australian Journal of Experimental Agriculture 48, 621-631. doi:10.1071/EA07133

Jouven M, Carrere P, Baumont R (2006) Model predicting dynamics of biomass, structure and digestibility of herbage in managed permanent pastures. 2. Model evaluation. Grass and Forage Science 61, 125-133. doi:10.1111/j.1365-2494.2006.00517.x

Lin LI (1989) A concordance correlation-coefficient to evaluate reproducibility. Biometrics 45, 255-268. doi:10.2307/2532051

Lodge GM, Murphy SR, Harden S (2003) Effects of grazing and management on herbage mass, persistence, animal production and soil water content of native pastures. 1. A redgrass-wallaby grass pasture, Barraba, North West Slopes, New South Wales. Australian Journal of Experimental Agriculture 43, 875-890. doi:10.1071/EA02188

McLean I, Blakeley S (2014) Animal equivalent methodology: a methodology to accurately and consistently calculate cattle grazing loads in northern Australia B.NBP.0779. Meat and Livestock Australia, Sydney, NSW.

McLean I, Holmes P, Counsell D (2014) The Northern beef report 2013. Northern beef situation analysis. Meat and Livestock Australia, Sydney, NSW.

Murphy SR (2010) 'Prime Facts: tropical perennial grasses - root depths, growth and water use efficiency.' (Department of Primary Industries: Tamworth)

O'Reagain P, Bushell J (2011) 'The Wambiana grazing trial: key learnings for sustainable and profitable management in a variable environment.' (Department of Employment, Economic Development and Innovation: Brisbane)

O'Reagain P, Bushell J, Holloway C, Reid A (2009) Managing for rainfall variability: effect of grazing strategy on cattle production in a dry tropical savanna. Animal Production Science 49, 85-99. doi:10.1071/ EA07187

O'Reagain P, Bushell J, Holmes B (2011) Managing for rainfall variability: long-term profitability of different grazing strategies in a northern Australian tropical savanna. Animal Production Science 51, 210-224. doi:10.1071/AN10106

O’Reagain P, Scanlan J, Hunt L, Cowley R, Walsh D (2014) Sustainable grazing management for temporal and spatial variability in north
Australian rangelands - a synthesis of the latest evidence and recommendations. The Rangeland Journal 36(3), 223-232. doi:10.1071/ RJ13110

Oreskes N, Shraderfrechette K, Belitz K (1994) Verification, validation, and confirmation of numerical-models in the earth-sciences. Science $\mathbf{2 6 3}$, 641-646. doi:10.1126/science.263.5147.641

Pembleton KG, Rawnsley RP, Jacobs JL, Mickan FJ, O'Brien GN, Cullen BR, Ramilan T (2013) Evaluating the accuracy of the Agricultural Production Systems Simulator (APSIM) simulating growth, development, and herbage nutritive characteristics of forage crops grown in the south-eastern dairy regions of Australia. Crop and Pasture Science 64, 147-164. doi:10.1071/CP12372

Pringle MJ, Allen DE, Dalal RC, Payne JE, Mayer DG, O'Reagain P, Marchant BP (2011) Soil carbon stock in the tropical rangelands of Australia: effects of soil type and grazing pressure, and determination of sampling requirement. Geoderma 167-168, 261-273. doi:10.1016/ j.geoderma.2011.09.001

Robertson SM (2006) Predicting pasture and sheep production in the Victorian Mallee with the decision support tool, GrassGro. Australian Journal of Experimental Agriculture 46, 1005-1014. doi:10.1071/ EA04034

Rykiel EJ (1996) Testing ecological models: the meaning of validation. Ecological Modelling 90, 229-244. doi:10.1016/0304-3800(95)00152-2

Sanford P, Cullen BR, Dowling PM, Chapman DF, Garden DL, Lodge GM, Andrew MH, Quigley PE, Murphy SR, King WM, Johnston WH, Kemp DR (2003) SGS Pasture Theme: effect of climate, soil factors and management on pasture production and stability across the high rainfall zone of southern Australia. Australian Journal of Experimental Agriculture 43, 945-959. doi:10.1071/EA02209

Scanlan JC, MacLeod ND, O'Reagain PJ (2013) Scaling results up from a plot and paddock scale to a property - a case study from a long-term grazing experiment in northern Australia. The Rangeland Journal 35, 193-200. doi:10.1071/RJ12084

Tedeschi LO (2006) Assessment of the adequacy of mathematical models. Agricultural Systems 89, 225-247. doi:10.1016/j.agsy.2005.11.004

Thornley JHM, Johnson IR (2000) 'Plant and crop modelling.' (Blackburn Press: Caldwell, NJ)

Tomkins NW, O'Reagain PJ, Swain D, Bishop-Hurley G, Charmley E (2009) Determining the effect of stocking rate on the spatial distribution of cattle for the subtropical savannas. The Rangeland Journal 31, 267-276. doi:10.1071/RJ07070

Tothill JC, Hargreaves JNG, Jones RM, McDonald CK (1992) BOTANAL: a comprehensive sampling procedure for estimating pasture yield and composition. 1. Field sampling. Tropical Agronomy Technical Memorandum No. 78. CSIRO Division of Tropical Crops and Pastures, Brisbane, Qld, Australia.

White TA, Johnson IR, Snow VO (2008) Comparison of outputs of a biophysical simulation model for pasture growth and composition with measured data under dryland and irrigated conditions in New Zealand. Grass and Forage Science 63, 339-349. doi:10.1111/j.1365-2494.2008. 00635.x 